\title{
Improving access to health care in a rural regional hospital in South Africa: Why do patients miss their appointments?
}

\begin{tabular}{|c|c|}
\hline \multicolumn{2}{|c|}{$\begin{array}{l}\text { Authors: } \\
\text { Lucy Frost } \\
\text { Louis S. Jenkins } \\
\text { Benjamin Emmink }\end{array}$} \\
\hline \multicolumn{2}{|c|}{$\begin{array}{l}{ }^{1} \text { Thames Valley and Wessex } \\
\text { Leadership Academy, United } \\
\text { Kingdom }\end{array}$} \\
\hline \multicolumn{2}{|c|}{$\begin{array}{l}{ }^{2} \text { Department of } \\
\text { Anthropology, Durham } \\
\text { University, United Kingdom }\end{array}$} \\
\hline \multicolumn{2}{|c|}{$\begin{array}{l}{ }^{3} \text { George Regional Hospital, } \\
\text { Western Cape Government, } \\
\text { South Africa }\end{array}$} \\
\hline \multicolumn{2}{|c|}{$\begin{array}{l}{ }^{4} \text { Division of Family Medicine } \\
\text { and Primary Care, } \\
\text { Stellenbosch University, } \\
\text { South Africa }\end{array}$} \\
\hline \multicolumn{2}{|c|}{$\begin{array}{l}{ }^{5} \text { George Regional Hospital, } \\
\text { Western Cape Government, } \\
\text { South Africa }\end{array}$} \\
\hline \multicolumn{2}{|c|}{$\begin{array}{l}\text { Corresponding author: } \\
\text { Louis Jenkins, } \\
\text { louis.jenkins@westerncape. } \\
\text { gov.za }\end{array}$} \\
\hline \multicolumn{2}{|c|}{$\begin{array}{l}\text { Received: } 18 \text { July } 2016 \\
\text { Accepted: } 18 \text { Nov. } 2016 \\
\text { Published: } 30 \text { Mar. } 2017\end{array}$} \\
\hline \multicolumn{2}{|c|}{$\begin{array}{l}\text { How to cite this article: } \\
\text { Frost L, Jenkins LS, Emmink B. } \\
\text { Improving access to health } \\
\text { care in a rural regional } \\
\text { hospital in South Africa: Why } \\
\text { do patients miss their } \\
\text { appointments? Afr J Prm } \\
\text { Health Care Fam Med. } \\
\text { 2017;9(1), a1255. https://doi. } \\
\text { org/10.4102/phcfm.v9i1.1255 }\end{array}$} \\
\hline \multicolumn{2}{|l|}{ Read online: } \\
\hline 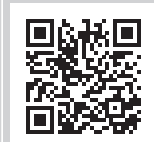 & $\begin{array}{l}\text { Scan this QR } \\
\text { code with your } \\
\text { smart phone or } \\
\text { mobile device } \\
\text { to read online. }\end{array}$ \\
\hline
\end{tabular}

Background: Access to health services is one of the Batho Pele ('people first') values and principles of the South African government since 1997. This necessitated some changes around public service systems, procedures, attitudes and behaviour. The challenges of providing health care to rural geographically spread populations include variations in socio-economic status, transport opportunities, access to appointment information and patient perceptions of costs and benefits of seeking health care. George hospital, situated in a rural area, serves 5000 outpatient visits monthly, with non-attendance rates of up to $40 \%$.

Objectives: The aim of this research was to gain a greater understanding of the reasons behind non-attendance of outpatient department clinics to allow locally driven, targeted interventions.

Methods: This was a descriptive study. We attempted to phone all patients who missed appointments over a 1 -month period $(n=574)$. Only $20 \%$ were contactable with one person declining consent. Twenty-nine percent had no telephone number on hospital systems, $7 \%$ had incorrect numbers, $2 \%$ had died and $42 \%$ did not respond to three attempts.

Results: The main reasons for non-attendance included unaware of appointment date (16\%), out of area $(11 \%)$, confusion over date (11\%), sick or admitted to hospital $(10 \%)$, family member sick or died (7\%), appointment should have been cancelled by clerical staff $(6 \%)$ and transport (6\%). Only $9 \%$ chose to miss their appointment. The other $24 \%$ had various reasons.

Conclusions: Improved patient awareness of appointments, adjustments in referral systems and enabling appointment cancellation if indicated would directly improve over two-thirds of reasons for non-attendance. Understanding the underlying causes will help appointment planning, reduce wasted costs and have a significant impact on patient care.

\section{Background}

Access to health care is recognised as a fundamental human right globally. ${ }^{1}$ In 1997, the South African national government embarked on a Batho Pele campaign aimed at improving service delivery to the public. Batho Pele is a Sesotho phrase meaning 'people first', committing the public service to serve all the people of South Africa. Access to health care is one of the Batho Pele values and principles, and it is also enshrined as a basic human right in the National Health Insurance (NHI) White Paper (2015) of South Africa. ${ }^{2}$ For this approach to succeed, some changes need to take place around public service systems, procedures, attitudes and behaviour.

Healthcare 2030 has set out a vision statement for health care in the Western Cape Province, endorsing 'Access to person-centred, quality care'. ${ }^{3}$ Access to health care has been widely debated, but one useful definition is 'providing the right service at the right time in the right place'. ${ }^{4}$

George Regional Hospital (GRH) serves approximately 605380 people from Eden and 73336 people from Central Karoo, covering an area of around $62185 \mathrm{~km} .{ }^{5}$ This poses challenges of how to provide access to care for such a geographically spread population. Confounding this further are issues of variation in socio-economic status, transport opportunities, access to appointment information and patient perceptions of costs and benefits of seeking health care. ${ }^{6}$

In July 2015, there were over 5000 outpatient visits to GRH. With such large numbers, when aiming to provide 'access to person-centred, quality care', the outpatient department (OPD) needs to be a focus. The frequency of 'did not attend' (DNA) rates for clinic appointments is an important

Copyright: (C 2017. The Authors. Licensee: AOSIS. This work is licensed under the Creative Commons Attribution License. 
measure of accessibility. ${ }^{6}$ Analysis of clinic attendance at GRH showed a variable DNA rate of between $20 \%$ and $40 \%$, depending on clinic specialty, between July and October 2015. This high non-attendance rate makes it difficult to develop reliable safety nets, and many of these patients are never seen in OPD.

Despite the complexities of providing outpatient care, there are few studies on reasons for non-attendance at outpatient clinics in South Africa. Some of the reasons for DNAs in South African OPDs include lack of finances, migration, forgetting and long distances from home to clinic. ${ }^{7,8,9}$

Internationally, other factors have also been identified, including patient apathy, concern over investigation or seeing junior staff. ${ }^{10,11}$ Illness beliefs have also been shown to have a large impact on a patients' choice to attend appointments. ${ }^{12}$

Although some of these challenges may be inherent in providing health care in a resource-limited setting, some interventions, such as reminder through short messaging systems (SMS), can be effective in reducing the rate of DNAs. ${ }^{13}$ An in-depth analysis of the major barriers could potentially allow targeted intervention leading to financial and administrative improvements, ${ }^{14}$ as well as ethical and clinical benefits of easier access to health care. ${ }^{15}$

The aim of this study was to explore factors contributing to patients missing their OPD appointments, and patients' ideas of how to improve the accessibility of OPD, allowing the development of a more patient-centred health service.

\section{Methods}

This was a descriptive study. A total of 574 patients did not attend their OPD appointment. Attempts were made to contact all patients, but only 115 were contacted. Ethics approval was obtained via Stellenbosch University Research Ethics Committee (N15/12/127). Semi-structured interviews were conducted telephonically with all adult patients who had missed appointments in the GRH OPD over a 1-month period in 2015, who were contactable and gave voluntary informed consent. Patients from specialties with OPD services in other areas of the hospital, and from obstetrics, were excluded. Telephonic interviews were chosen because of previously reported high response rates from this method ${ }^{11}$ and difficulties following patients up via other means. Patient details and telephone numbers were obtained through the hospital information system (CliniCom) (see Figure 1).

The interviews were semi-structured, using a combination of qualitative and quantitative questions, and were conducted by the first author, a clinician with health research experience. The interview guide contained questions about demographics, factors influencing non-attendance, perceptions of their appointment and their health and suggestions for improving the accessibility of OPD (available on request from the

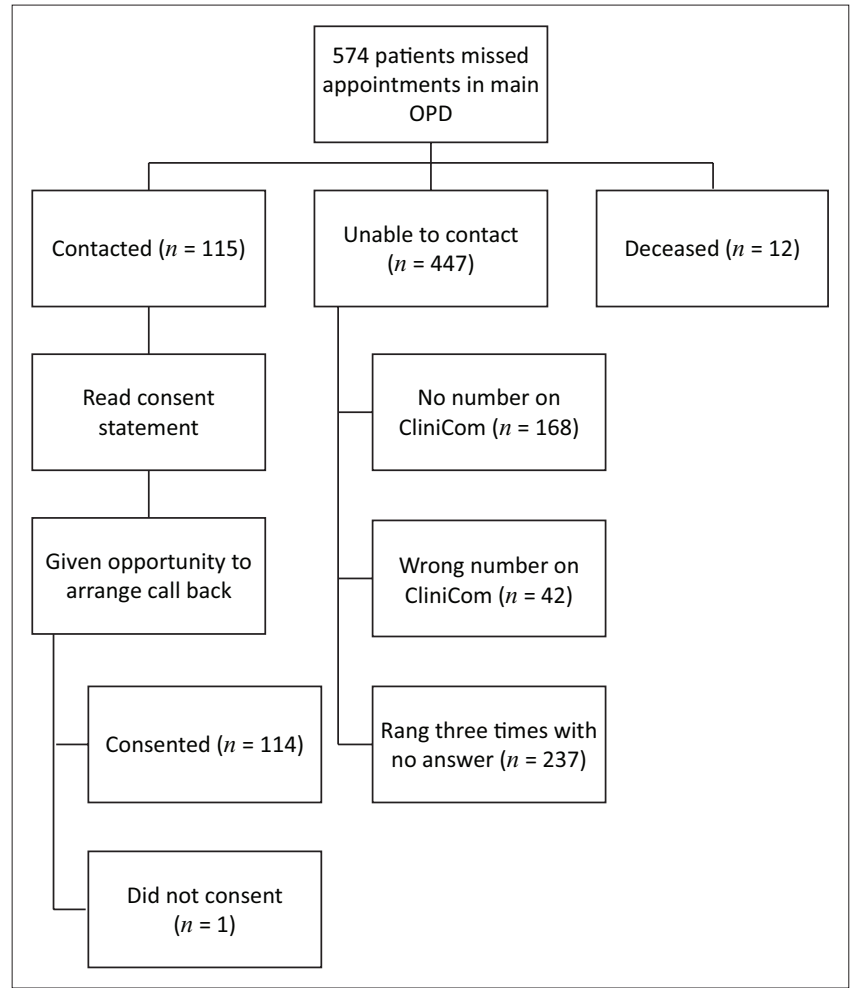

Source: (CliniCom), Department of Health

FIGURE 1: Outcomes of attempted patient contacts.

corresponding author). Interpreters were used where necessary to allow interviews to be conducted in the participants' preferred language (English, Afrikaans or Xhosa). Several participants declined to answer specific questions, affecting the total numbers of responses for that question. For this reason, raw numbers are given so this is clear.

Analysis of quantitative interview data was done using descriptive statistics. Qualitative data were manually analysed using a thematic approach. Two researchers coded all qualitative responses. Codes were then compared and adjusted until there was an agreement among the researchers.

Anonymity was maintained through allocating each participant an 'interview code', which was the only identifier attached to the data. Interview data and participant details were stored separately, each in a password-protected file. Confidentiality was maintained, with no health care professionals aware of which patients participated in the study. In the case that someone other than the patient answered the phone, no patient details, clinical information or information about the purpose of the call was given. A scripted information and consent statement was read to each participant; opportunities were given for any questions, and patients were informed that they could withdraw consent at any point. All participants were given an opportunity to arrange a call at a later time to give them time to consider their involvement. Verbal consent was obtained before continuing with the interview. 


\section{Results}

There were 115 successful contacts from a total of 574 attempts, and 114 of these patients consented to participate (see Table 1). The mean age was 53.2 years (range 20-86).

TABLE 1: Characteristics of study participants.

\begin{tabular}{|c|c|c|}
\hline Characteristics & $\begin{array}{c}\text { Number of } \\
\text { participants }\end{array}$ & $\begin{array}{c}\text { Percentage of total } \\
\text { participants (\%) }\end{array}$ \\
\hline \multicolumn{3}{|l|}{ Preferred language $(n=114)$} \\
\hline English & 19 & 16.7 \\
\hline Afrikaans & 72 & 63.2 \\
\hline Xhosa & 23 & 20.2 \\
\hline \multicolumn{3}{|l|}{ Gender $(n=113) \dagger$} \\
\hline Male & 43 & 38.1 \\
\hline Female & 70 & 62.0 \\
\hline \multicolumn{3}{|l|}{ Highest level of education ( $n=114)$} \\
\hline Never attended & 3 & 2.6 \\
\hline Primary & 22 & 19.3 \\
\hline Secondary & 78 & 68.4 \\
\hline University & 3 & 2.6 \\
\hline Postgraduate qualification & 2 & 1.8 \\
\hline Undisclosed & 6 & 5.3 \\
\hline \multicolumn{3}{|l|}{ Employment status ( $n=114$ ) } \\
\hline Employed full-time & 21 & 18.4 \\
\hline Employed part-time & 12 & 10.5 \\
\hline Unemployed or home duties & 40 & 35.1 \\
\hline Student & 0 & 0 \\
\hline Pensioner & 37 & 32.5 \\
\hline Undisclosed & 4 & 3.5 \\
\hline \multicolumn{3}{|c|}{ Usual method of transport to hospital $(n=111)$} \\
\hline Own transport & 39 & 35.1 \\
\hline HealthNet bus & 23 & 20.7 \\
\hline Minibus or taxi & 15 & 13.5 \\
\hline Go George bus & 13 & 11.7 \\
\hline Hired service & 9 & 8.1 \\
\hline Walk & 6 & 5.4 \\
\hline Driven by family member or friend & 5 & 4.5 \\
\hline Ambulance & 1 & 0.9 \\
\hline \multicolumn{3}{|l|}{ Clinic booked $(n=114)$} \\
\hline Ophthalmology & 20 & 17.5 \\
\hline Orthopaedics & 19 & 16.7 \\
\hline Surgery & 12 & 10.5 \\
\hline Gynaecology & 12 & 10.5 \\
\hline Oncology & 10 & 8.8 \\
\hline Respiratory & 7 & 6.1 \\
\hline ENT & 6 & 5.3 \\
\hline Cardiology & 6 & 5.3 \\
\hline Rheumatology & 6 & 5.3 \\
\hline Family medicine & 5 & 4.4 \\
\hline Metabolic & 5 & 4.4 \\
\hline Urology & 3 & 2.6 \\
\hline Colposcopy & 2 & 1.8 \\
\hline Internal medicine & 1 & 0.9 \\
\hline \multicolumn{3}{|c|}{ Estimated time taken to get from home to hospital $(n=107)$} \\
\hline$<15 \min$ & 14 & 13.1 \\
\hline $15-29 \min$ & 16 & 15.0 \\
\hline $30-59 \mathrm{~min}$ & 22 & 20.6 \\
\hline $60-119 \min$ & 32 & 29.9 \\
\hline $120-179 \mathrm{~min}$ & 13 & 12.2 \\
\hline$\geq 180 \mathrm{~min}$ & 10 & 9.4 \\
\hline
\end{tabular}

Source: (CliniCom), Department of Health

$\dagger$, One person had the wrong participant code attached and therefore unable to determine gender.
There was a wide range of reasons given for missing OPD appointments (see Table 2). The most common reasons given were that participants were unaware that they had an appointment on that date $(15.9 \%)$ or were confused about when the appointment was $(10.6 \%)$, they were out of town at the time $(10.6 \%)$, they were sick or admitted to hospital $(9.7 \%)$ or they chose not to attend as they did not think it was needed $(8.8 \%)$. Clerical issues both in OPD and in referring centres were raised, specifically, appointments being recorded for the participants incorrectly and participants being told appointments were cancelled but not being cancelled on CliniCom. Five participants contacted had actually attended their appointments, demonstrating an issue with attendance recording systems.

When participants were asked whether they understood why they had an appointment at the hospital, $91.8 \%$ $(n=101)$ felt that they did, with $6.4 \%(n=7)$ participants not understanding and $1.8 \%(n=2)$ participants being unsure. When participants were asked whether they thought it was necessary for them to attend their appointment, $85.1 \%(n=97)$ thought it was necessary, $9.7 \%(n=11)$ thought it was not necessary and $1.8 \%(n=2)$ were unsure.

Overall, 95.4\% $(n=103)$ participants were satisfied with the OPD, $1.9 \%(n=2)$ were unsure and 2.9\% $(n=3)$ were not satisfied. Reasons given for being satisfied included the friendliness of staff, cleanliness and provision of high-quality medical care. The participants who were not satisfied gave the following reasons:

(1) advised by a doctor in OPD that they could be followed up at a local clinic rather than hospital

(2) unable to afford services

(3) felt the staff were rude regarding a psychiatric diagnosis.

TABLE 2: Reasons for missing OPD appointments.

\begin{tabular}{lcc}
\hline Reasons for missing appointment & Number & $\begin{array}{c}\text { Percentage of } \\
\text { participants (\%) }\end{array}$ \\
\hline Unaware of appointment date & 18 & 15.9 \\
Out of George & 12 & 10.6 \\
Confusion over appointment date & 12 & 10.6 \\
Sick or admitted to hospital & 11 & 9.7 \\
Chose not to attend & 10 & 8.8 \\
Family member sick or died & 8 & 7.1 \\
Clerical error - appointment should have & 8 & 7.1 \\
been cancelled & 7 & 6.2 \\
Transport difficulties & 5 & 4.4 \\
Forgot about appointment & 5 & 4.4 \\
Patient attended appointment & 5 & 4.4 \\
Told by medical professional not to come & 2 & 1.8 \\
Attended but not seen & 2 & 1.8 \\
Another clashing appointment & 2 & 1.8 \\
\hline Work commitments & 2 & 1.8 \\
Difficulty cancelling appointments & 4 & 3.5 \\
\hline Miscellaneous $\dagger$ & & \\
\hline Source: Personat comm & 5 & \\
\hline
\end{tabular}

Source: Personal communication with study participants

$\dagger$, Miscellaneous reasons were participant attended OPD, but queues were too long at admissions and OPD, so they left; too many appointments; participant felt unable to make it that day (no other reason given); and contradictory SMS messages meant participant thought appointment was cancelled. 
Despite being satisfied overall with OPD services, issues such as waiting times and staff communication were raised multiple times.

Participants were asked what the hospital could do to make it easier to attend appointments. By far, the most common response was that the hospital should remind patients about appointments by SMS or phone call $(n=47,44.8 \%)$. Thirty-nine percent $(n=41)$ of participants felt nothing could be improved. Other reasons included improved transportation $(n=8,7.6 \%)$, reduced waiting times $(n=6$, $5.7 \%)$, changes to how appointments are scheduled $(n=3$, $2.9 \%)$, transfer of care to a more local clinic or hospital $(n=2,1.9 \%)$ and easier cancellation systems $(n=2,1.9 \%)$. Reasons given by one participant each included liaising with employers, liaising with family members and better communication with clinics. One participant also made a suggestion about appointment and transportation bookings that was already in place, suggesting a lack of awareness of the current systems.

\section{Ethical consideration}

Ethics approval was obtained via Stellenbosch University Research Ethics Committee (N15/12/127).

\section{Discussion}

The most common reason given for participants not attending was that they were unaware of their appointment. The majority of these participants had seen a clinician at a level-one hospital or clinic that had referred the participant, but the participant was not aware of being contacted by the hospital with the date. This was a feasible scenario given many of the referral systems requiring OPD ward clerks to contact patients with appointment information at a later date, often involving the referring centre to help contact the patient. A move towards giving patients an appointment date, when they are still sitting with the referrer would combat this. This was a new issue that had not been raised in previous research in South Africa or internationally. There were also related issues such as confusion over dates $(10.6 \%)$ and appointments that should have been cancelled (7.1\%), which could be improved with robust administrative systems.

The second most common reason was that the participant said they were out of the area at the time of appointment $(10.6 \%)$, often in the Eastern Cape or the Karoo. This has been found to be a significant problem elsewhere. ${ }^{7,8}$ Although all participants said this was a temporary arrangement, multiple participants said it would be useful to have their care delivered closer to home. Given the wide geographical catchment area of GRH and the fact that almost $10 \%$ of participants would have travelled over $3 \mathrm{~h}$ to get to GRH, it is unsurprising that distance is a factor. More surprisingly is that issues that would be expected to play into this, such as transport, only came up infrequently $(6.2 \%)$.
Although many of the findings of this study were in accordance with other research, factors that came up significantly less than other studies included forgetting appointments and transport issues. ${ }^{8,9}$ Financial difficulties came up in $95 \%$ interviews in one study ${ }^{7}$, yet were not given as a significant factor influencing missed appointments in any of these interviews.

SMS or phone reminder systems were a popular suggestion for improvement. The hospital currently uses SMS reminders in certain specialties, and this is something that could be rolled out through the OPD. However, strong evaluative frameworks are required when doing so, as evidence is inconclusive for $\mathrm{SMS}^{13}$ and phone $^{16}$ reminders in South Africa. The fact that only $20 \%$ of participants who missed appointments were contactable on the given telephone numbers indicated this as a specific challenge to focus on. High cell phone turnover, reluctance to give accurate number for billing purposes and use of friends or family members' numbers may all have contributed. This supports the recommendation of providing patients with appointment dates at point of care.

Based on the reasons given for missing appointments, approximately $50 \%$ of the appointments could have been cancelled, demonstrating a significant opportunity for improvement. The introduction of a toll-free telephone number or SMS system where patients were able to rebook or cancel appointments would encourage patients to inform the hospital of changes. This would allow them to rebook appointments, whereas many are currently getting lost in the system, and would allow other patients to use the appointment.

There were several limitations to this study. We were only able to contact $20 \%$ of eligible patients, potentially biasing the reasons given for non-attendance. To try and minimise this, we attempted to contact a larger sample, using various available contact numbers, and tried to phone people at different times of the day to reach the most representative group possible. The self-reporting nature of interviews is prone to social desirability bias. This may have created a bias towards hospital factors, rather than patient factors. However, similar studies have found that patients will admit to patient factors. ${ }^{7,89}$ Although semi-structured telephone interviews allowed us to reach a higher number of patients than other methodologies were likely to, it did not allow in-depth exploration of illness and health beliefs. These have been found to greatly influence attendance and would, therefore, be useful to explore further in the future. ${ }^{12}$

Some people have argued that staff and patient apathy may preclude meaningful DNA reductions. ${ }^{11}$ However, we found staff very motivated across specialties and external hospitals, and had multiple requests for specialty-specific analysis to target their main problems and the resources to replicate the study in other contexts. Although it is harder to assess patient motivation, the variable attendance across specialties 
suggests that motivation has a big impact. Many of the barriers, such as transport, are equally difficult for all patients but some clinics had a much higher non-attendance. Other studies showed that targeted interventions can have significant and persisting effects. ${ }^{17}$

Exploring reasons for non-attendance is difficult as few approaches are bias-free. In order to get as complete an understanding as possible of the challenges patients face in reaching their OPD appointments, it is important to address the question with multiple methodologies. Further quantitative analysis of some of the demographic and clinical factors would be beneficial, including outcomes such as distances travelled, age, gender and previous number of appointments attended. If specific at-risk groups were targeted through this, then more in-depth interviews and focus groups could be used to get a more thorough understanding of their challenges. This could include more of a focus on health and illness beliefs, which was difficult to obtain in this study.

\section{Conclusion}

The aim of this study was to explore factors contributing to patients missing their OPD appointments and patients' ideas of how to improve the accessibility of OPD, allowing the development of a more patient-centred health service. A greater understanding of reasons behind non-attendance has allowed more targeted interventions to maximise attendance, addressing both patient and hospital factors.

\section{Acknowledgements}

The patients interviewed, the outpatient department (OPD) administrative and nursing staff and hospital management, particularly also the CEO, Mr Mike Vonk, are thanked for their time and support for this study.

Thanks also go to the Tropical Health and Education Trust and Thames Valley and Wessex Leadership Academy for funding the Improving Global Health through Leadership Development Fellowship for Dr Frost, through which this work was completed.

\section{Competing interests}

The authors declare that there has been no financial or personal relationship(s) that may have inappropriately influenced the writing of this article.

\section{Authors' contributions}

L.F. conceptualised the research, collected the data and drafted the first manuscript. L.S.J. was the project leader, helped with the project design, data analysis, and writing up of the results and the final article. B.E. made conceptual contributions and helped with the writing of the final article.

\section{References}

1. World Health Organisation. Constitution of the World Health Organisation, 45th ed. [homepage on the Internet]. 2006 [cited 2016 May 9]. Available from http:// www.who.int/governance/eb/who_constitution_en.pdf

2. Department of Health, Republic of South Africa. National Health Insurance for South Africa: Towards Universal Health Coverage. Version 40 [homepage on the Internet]. 2015 [cited 2016 May 9] Available from https://www.health-e.org.za/ wp-content/uploads/2015/12/National-Health-Insurance-for-South-AfricaWhite-Paper.pdf

3. Western Cape Government Health. Healthcare 2030: The road to wellness. Cape Town: Department of Health; 2014

4. Rogers A, Flowers J, Pencheon D. Improving access needs a whole systems approach. BMJ. 1999;319(7214):866-867. https://doi.org/10.1136/bmj.319. 7214.866

5. Western Cape Government Health. Annual performance plan 2014/2015. Cape Town: Department of Health; 2014

6. Gaede B, Versteeg M. Chapter 9 - The state of the right to health in rural South Africa. In: Padarath A, English R, editors. South African Health Review 2011. Durban: Health Systems Trust; 2011; p. 99-106.

7. Ntamo NP, Buso D, Longo-Mbenza B. Factors affecting poor attendance for outpatient physiotherapy by patients discharged from Mthatha general hospital with a stroke. S Afr J Physiother [serial online]. 2013;69(3):13-18. [cited 2016 May 9]. Available from: http://www.physiosa.org.za

8. Ngwenya B, van Zyl D, Webb E. Factors influencing non-attendance of clinic appointments in diabetic patients at a Gauteng hospital in 2007/2008. J Endocrino Metab Diabetes S Afr. 2009;14(2):106-110. https://doi.org/10.1080/22201009.2 009.10872203

9. Van der Meer G, Loock JW. Why patients miss follow-up appointments: A prospective control-matched study. East Afr J Public Health. 2008;5(3):154-156. https://doi.org/10.4314/eajph.v5i3.38994

10. Martin C, Perfect T, Mantle G. Non-attendance in primary care: The views of patients and practices on its causes, impact and solutions. Fam Pract. 2005;22(6):638-643. https://doi.org/10.1093/fampra/cmi076

11. Murdock A, Rodgers C, Lindsay $H$, Tham $T$. Why do patients not keep their appointments? Prospective study in a gastroenterology outpatient clinic. J Roy Soc Med. 2002;95(6):284-286. https://doi.org/10.1258/jrsm.95.6.284

12. Cooper A, Lloyd G, Weinman J, Jackson G. Why patients do not attend cardiac rehabilitation: Role of intentions and illness beliefs. Heart. 1999;82(2):234-236. https://doi.org/10.1136/hrt.82.2.234

13. Youssef A, Alharthi H, Al Khaldi O, Alnaimi F, Alsubaie N, Alfariss N. Effectiveness of text message reminders on nonattendance of outpatient clinic appointments J T U Med Sci. 2014;9(1):23-29. https://doi.org/10.1016/j.jtumed.2013.10.001

14. Moore CG, Wilson-Witherspoon P, Probst JC. Time and money: Effects of no-shows at a family practice residency clinic. Fam Med. 2001;33(7):522-527.

15. Harris B, Goudge J, Ataguba JE, et al. Inequities in access to health care in South Africa. J Public Health Policy 2011;32 Suppl 1:S102-S123. https://doi.org/10.1057/ jphp. 2011.35

16. Corfield L, Schizas A, Noorani A, Williams A. Non-attendance at the colorectal clinic: A prospective audit. Ann R Coll Surg Engl. 2008;90(5):377-380. https://doi. org/10.1308/003588408×30117

17. Rindfleisch K, Pruszynski J, Frey J. A multi-method intervention to reduce no-shows in an urban residence clinic Clark DuMontier. Fam Med. 2013;45(9): 